Article

\title{
Determination of Clobazam and Its Major Metabolite $N$-desmethylclobazam in Human Plasma with High-Performance Liquid Chromatography
}

\author{
Fadumo Ahmed Isse (D) and Sherif Hanafy Mahmoud *(D)
}

Faculty of Pharmacy and Pharmaceutical Sciences, University of Alberta, Edmonton, AB T6G 2E1, Canada; fisse@ualberta.ca

* Correspondence: smahmoud@ualberta.ca; Tel.: +1-780-492-5364

Citation: Isse, F.A.; Mahmoud, S.H. Determination of Clobazam and Its Major Metabolite

$\mathrm{N}$-desmethylclobazam in Human Plasma with High-Performance Liquid Chromatography. Analytica 2021, 2, 57-65. https://doi.org/ 10.3390 /analytica2030007

Academic Editor: Marcello Locatelli

Received: 9 June 2021

Accepted: 5 July 2021

Published: 7 July 2021

Publisher's Note: MDPI stays neutral with regard to jurisdictional claims in published maps and institutional affiliations.

Copyright: (c) 2021 by the authors. Licensee MDPI, Basel, Switzerland. This article is an open access article distributed under the terms and conditions of the Creative Commons Attribution (CC BY) license (https:/ / creativecommons.org/licenses/by/ $4.0 /)$.

\begin{abstract}
Clobazam (CLB) is a benzodiazepine that is used in many types of epilepsy. Although therapeutic drug monitoring (TDM) of CLB is not routine, there is evidence that TDM may be of value in conditions where pharmacokinetic alterations are suspected. Therefore, determination of both CLB and its active metabolite concentrations is essential for TDM. Herein, we present a simple and practical method for determination of CLB and N-desmethylclobazam (NDMCLB) in human plasma by highperformance liquid chromatography (HPLC). The drugs were extracted by hexane:dichloromethane $(1: 1, v / v)$ from $0.3 \mathrm{~mL}$ plasma. The separation was carried out with a $\mathrm{C} 18$ reverse phase column using a mobile phase of water:acetonitrile $(57: 43, v / v)$ pumped at $0.8 \mathrm{~mL} / \mathrm{min}$. The analytes were detected at $228 \mathrm{~nm}$. The method was linear over the concentration range $20-500 \mathrm{ng} / \mathrm{mL}$ for CLB and 200-3000 ng/mL for NDMCLB. The intra-day coefficient of variation (CV) was $<10 \%$ for CLB and $<6 \%$ for NDMCLB, while the inter-day CV for CLB was $<16 \%$. The metabolite inter-day CV was $<6 \%$. The accuracy of intra- and inter-day assessments determined for CLB and NDMCLB was within $\pm 10 \%$. This paper describes a rapid, reliable, and simple method for measuring CLB and its metabolite NDMCLB in human plasma. This UV-HPLC procedure offers acceptable precision and accuracy to quantify CLB and its metabolite in human plasma.
\end{abstract}

Keywords: clobazam; desmethylclobazam; high-performance liquid chromatography; plasma

\section{Introduction}

Clobazam (CLB), is a benzodiazepine antiepileptic drug that has been shown to be effective in many types of refractory epilepsy and has been in use since 1984 [1-3]. Its 1,5-benzodiazepine structure, as opposed to that of the traditional 1,4 benzodiazepines, confers it unique characteristics. It preferentially binds to the $\alpha 2$ subunit of GABA-A receptors over $\alpha 1$, rendering CLB less sedating and more suitable for chronic administration than other benzodiazepines [1-3]. Although therapeutic drug monitoring (TDM) of CLB is not routine, there is growing evidence that TDM may be of value in conditions where pharmacokinetic alterations are suspected, such as in the case of drug-drug interactions [4], liver disease [5], and extremes of age [6]. CLB is mainly metabolized by the liver with negligible renal elimination. $N$-desmethylclobazam (NDMCLB) is an active metabolite resulting from the $N$-demethylation of CLB (Figure 1). It has a longer half-life than the parent drug and is believed to contribute to the pharmacological effects of CLB [7]. Therefore, determination of the concentrations of both the parent drug and its metabolite is essential for TDM. The suggested reference ranges for CLB and NDMCLB are 30-300 ng $/ \mathrm{mL}$ and 300-3000 ng/mL, respectively [7]. Several analytical procedures have been reported to determine CLB and NDMCLB concentrations in biological samples, utilizing various techniques including gas-liquid chromatography (GLC) [8-10], liquid chromatography tandem mass spectrometry (LC-MS/MS) [11-13], and high-performance liquid chromatography (HPLC) [14-20]. Herein, we present a rapid, reproducible, simple, and sensitive HPLC-UV 
method for quantifying CLB and NDMCLB in human plasma. The method utilizes a single liquid-liquid extraction step, small volumes of samples $(0.3 \mathrm{~mL}$ as opposed to $1 \mathrm{~mL}$ in most methods) [17,18,21-24], and a simple mobile phase mixture (acetonitrile/water as opposed to using buffers) [20]. In addition, the method quantifies CLB and NDMCLB over the suggested reference range in patients with epilepsy, and is thus practical for TDM purposes.

A<smiles>CN1C(=O)CC(=O)N(c2ccccc2)c2cc(Cl)ccc21</smiles>

B<smiles>O=C1CC(=O)N(c2ccccc2)c2cc(Cl)ccc2N1</smiles>

c<smiles>CN1C(=O)CN=C(c2ccccc2)c2cc(Cl)ccc21</smiles>

Figure 1. Chemical structures of (A) clobazam (CLB); (B) the metabolite $\mathrm{N}$-desmethylclobazam (NDMCLB); and (C) the internal standard used (diazepam).

\section{Materials and Methods}

\subsection{Reagents}

CLB (certified reference material; purity 99.9\%), diazepam (certified reference material; purity $\leq 100 \%$ ), NDMCLB (certified reference material; purity $100 \%$ ), and HPLC grade acetonitrile and hexane were obtained from Sigma-Aldrich (Oakville, ON, Canada). HPLC grade water was from Fisher Scientific (Edmonton, AB, Canada). Dichloromethane was purchased from Caledon Laboratories Ltd. (Georgetown, ON, Canada) and pooled human plasma was from Cedarlane Laboratories (Burlington, ON, Canada).

\subsection{Instrument}

The experiment was performed using an HPLC-UV system (Shimadzu, Kyoto, Japan) that consisted of a system controller (CBM-20A), an autosampler (SIL-10-AF), a binary pump (LC-10 AD), and a UV-Vis detector (SPD-10A). The separation was carried out by using a C18 reverse phase ZORBAX ${ }^{\circledR}$ Eclipse XDB column $(4.6 \mathrm{~mm} \times 150 \mathrm{~mm}, 5 \mu \mathrm{m})$ (Agilent Technologies Inc., Santa Clara, CA, USA) with a KrudKatcher ${ }^{\circledR}$ Ultra guard column 
(Phenomenex, Torrance, CA, USA). LabSolutions ${ }^{\circledR}$ software (Shimadzu, Kyoto, Japan) was utilized for data acquisition and chromatographic integration.

\subsection{Chromatographic Conditions}

Compounds were eluted by using an isocratic mixture of mobile phase (wateracetonitrile, $57: 43, v / v$ ) and pumped at $0.8 \mathrm{~mL} / \mathrm{min}$. All the drugs were detected at a wavelength of $228 \mathrm{~nm}$. The run time was $15 \mathrm{~min}$.

\subsection{Standard Stock and Working Solutions}

Stock standard solution of $100 \mu \mathrm{g} / \mathrm{mL}$ of CLB was prepared by diluting the commercially available $1 \mathrm{mg} / \mathrm{mL}$ solution with methanol and stored at $-20^{\circ} \mathrm{C}$ until needed. Working solutions of $1000 \mathrm{ng} / \mathrm{mL}$ and $100 \mathrm{ng} / \mathrm{mL}$ of CLB were freshly prepared each day. CLB $1000 \mathrm{ng} / \mathrm{mL}$ working solution was prepared by diluting the standard solution with methanol. Then, CLB $100 \mathrm{ng} / \mathrm{mL}$ working solution was prepared by diluting the $1000 \mathrm{ng} / \mathrm{mL}$ solution with HPLC grade water. Both working solutions were used to prepare CLB serial dilutions in plasma.

Standard solution of $100 \mu \mathrm{g} / \mathrm{mL}$ of NDMCLB in methanol (commercially available) was used as working solution to prepare serial dilutions of NDMCLB concentrations $\geq$ $1000 \mathrm{ng} / \mathrm{mL}$ in plasma. Additionally, it was used for preparing the $1000 \mathrm{ng} / \mathrm{mL}$ working solution (by dilution with methanol), which was used to prepare NDMCLB serial dilutions in plasma (dilutions with concentrations $<1000 \mathrm{ng} / \mathrm{mL}$ ). An internal standard solution of $500 \mathrm{ng} / \mathrm{mL}$ diazepam was freshly prepared daily from commercially available $1000 \mathrm{ug} / \mathrm{mL}$ diazepam solution by dilution with HPLC grade water.

\subsection{Calibration Standards and Quality Control Samples}

Serial dilutions of CLB and NDMCLB concentrations in blank human plasma ranging from $20-500 \mathrm{ng} / \mathrm{mL}$ and $200-3000 \mathrm{ng} / \mathrm{mL}$, respectively, were prepared to construct calibration curves of CLB and its metabolite. Four quality control (QC) samples were prepared along with the calibration concentrations to validate our method: Lowest limit of quantification (LLOQ), a low level, LQC ( $3 \times$ LLOQ), a middle level, MQC (around the middle of the range of calibration concentrations), and a high level, HQC (around 75-95\% of the upper limit of quantification).

\subsection{Sample Preparation}

Each $0.3 \mathrm{~mL}$ of human plasma spiked with CLB and/or NDMCLB was mixed with $150 \mu \mathrm{L}$ of $500 \mathrm{ng} / \mathrm{mL}$ diazepam as an internal standard (IS). Samples were vortex mixed for $45 \mathrm{~s}$. Then, organic solvents containing hexane and dichloromethane $(1: 1, v / v)$ were added to the samples. Mixtures were then vortex mixed for $5 \mathrm{~min}$, and then centrifuged at $2000 \mathrm{rpm}$ for $10 \mathrm{~min}$. The organic layer was then transferred to clean test tubes and dried by a SpeedVac ${ }^{\circledR}$ Vacuum Concentrator (Thermo Fisher Scientific, Waltham, MA, USA). Residue was reconstituted by $125 \mu \mathrm{L}$ of mobile phase (water-acetonitrile, 57:43, $v / v$ ) and an $80 \mu \mathrm{L}$ volume of the reconstituted sample was injected into the HPLC. The column was washed with pure methanol between each set of sample analyses.

\subsection{Method Validation}

For method validation, we evaluated the method's linearity, selectivity, sensitivity, precision, accuracy, and extraction recovery. The method was validated based on guidelines on bioanalytical method validation by the European Medicines Agency (EMA, 2011).

\subsubsection{Linearity}

The linearity of the method was assessed by constructing calibration curves by plotting peak area ratios (CLB and NDMCLB/internal standard) vs. the nominal concentrations of both drugs' calibration standards. Linear regression was performed to calculate the slope, intercept, and the coefficient of determination $\left(\mathrm{r}^{2}\right)$ calculations for each calibration curve. 


\subsubsection{Selectivity and Sensitivity}

Blank human plasma samples were injected before each run $(n=6)$. The method's selectivity was assessed by the lack of peaks retained at the retention times of the analytes and IS when blank samples were injected. LLOQ was the lowest concentrations in the calibration curve with precision $<20 \%$ and accuracy within $\pm 20 \%$. In addition, the signal of the LLOQ also had to be at least 5 times higher than that of blank plasma signal.

\subsubsection{Precision and Accuracy}

The inter-day and intra-day accuracy and precision of the method were evaluated by analyzing five replicates of QC samples spiked with the CLB and its metabolite at 4 QC levels $(20,60,150,400 \mathrm{ng} / \mathrm{mL}$ and 200, 600, 1600, $2500 \mathrm{ng} / \mathrm{mL}$, respectively) in runs on three different days. The precision was presented as coefficient of variation $(\mathrm{CV}, \%)$ while the accuracy was expressed as percent error (\%, error).

\subsubsection{Recovery}

The mean extraction recoveries of CLB and NDMCLB were obtained by comparing the peak areas of the extracted samples at LQC, MQC, and HQC levels with those obtained from extracts of blank plasma spiked with equivalent concentrations of CLB and NDMCLB post extraction.

\section{Results}

\subsection{Liquid Chromatography Method Development}

The method was optimized by performing different liquid chromatography experimentations. To enhance the separation of the peak and signal intensity, the following mobile phase compositions were tested: 50:50, 43:57, and 57:43, $v / v$ acetonitrile-water with different volumes of injections. The mobile phase composition and sample injection volume that gave clear separation and high peak intensity were $57: 43, v / v$ (water-acetonitrile) and $80 \mu \mathrm{L}$, respectively. The elution times determined for CLB and NDMCLB were 8.32 and $5.82 \mathrm{~min}$, respectively, while diazepam was eluted at $10.78 \mathrm{~min}$ (Figure 2). Additional non-interfering peaks were observed, most likely from the plasma and/or standard impurities, as we did not see any sample carryover effect. Nevertheless, we were able to achieve calibration curves with excellent linearity. With regard to sample extraction, we tried a few solvents for extraction, including hexane alone, diethyl ether alone, dichloromethane alone, and combinations of them at different ratios. A combination of hexane and dichloromethane $(1: 1, v / v)$ provided superior extraction recovery.

\subsection{Method Validation}

\subsubsection{Linearity}

The linearity of the method was assessed by running both pure and extracted samples over the concentration ranges of 20-500 $\mathrm{ng} / \mathrm{mL}$ for CLB and 200-3000 ng/mL for NDMCLB. The peak area ratios were linear over the tested concentration ranges for both CLB and NDMCLB with $\mathrm{r}^{2}>0.99$ (Figure 3).

\subsubsection{Selectivity and Sensitivity}

As shown in Figure 2, there were no interfering peaks with both CLB and NDMCLB. Additionally, there were no peaks seen at the retention time of the internal standard (diazepam). In addition, there were no carryover effects when we ran blank plasma, mobile phase, and HPLC water multiple times at the beginning of the run and in between runs. The LLOQ was found to be $20 \mathrm{ng} / \mathrm{mL}$ for CLB and $200 \mathrm{ng} / \mathrm{mL}$ for NDMCLB. 
A

$\mathrm{mV}$

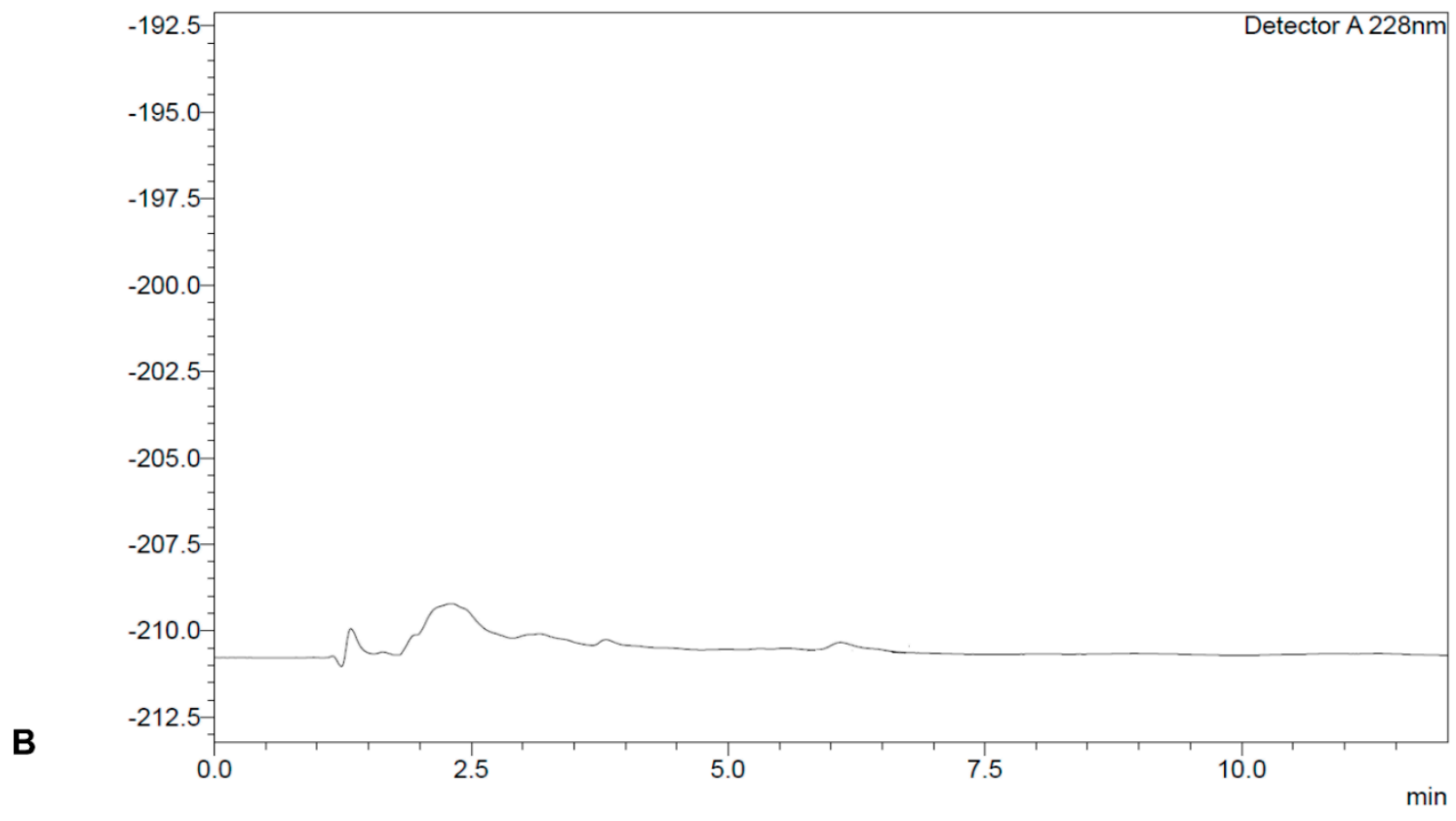

$\mathrm{mV}$

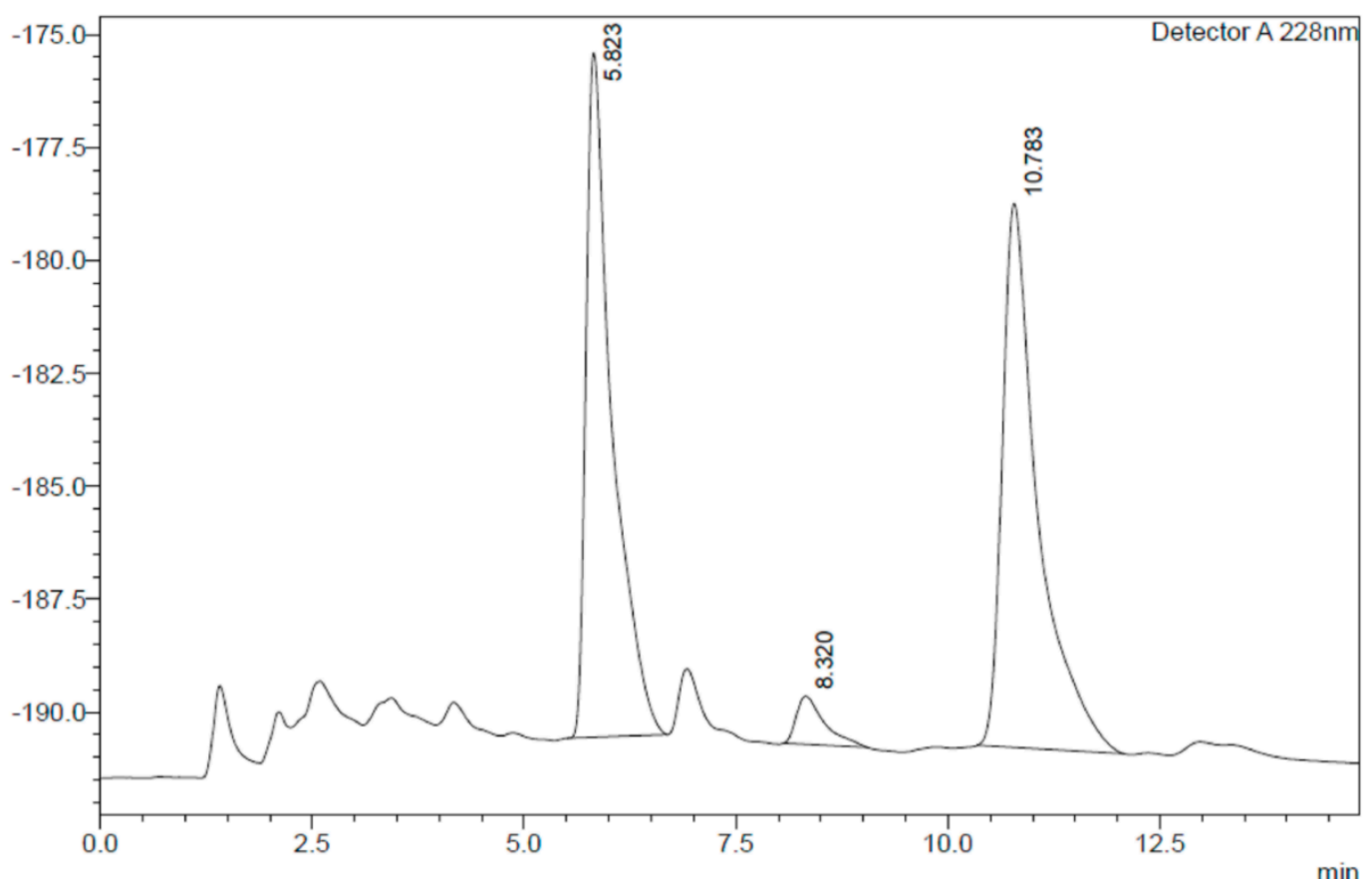

Figure 2. (A) A chromatogram of blank plasma; (B) a chromatogram of a human plasma sample spiked with $20 \mathrm{ng} / \mathrm{mL}$ of clobazam (CLB) and $200 \mathrm{ng} / \mathrm{mL}$ of $\mathrm{N}$-desmethylclobazam (NDMCLB). Retention times determined for CLB and NDMCLB were 8.32 and $5.82 \mathrm{~min}$, respectively, while for the internal standard (IS), diazepam was retained at $10.78 \mathrm{~min}$. The area of the peak eluted at $6.093 \mathrm{~min}$ in the blank sample is $4880 \mathrm{mV} \cdot \mathrm{min}$. The area of the LLOQ peak of NDMCLB (depicted in (B)) is $325,589 \mathrm{mV} \cdot \mathrm{min}$, which is $\sim 67$ times higher that of blank plasma signal, which is within the acceptable selectivity validation criteria. 
A

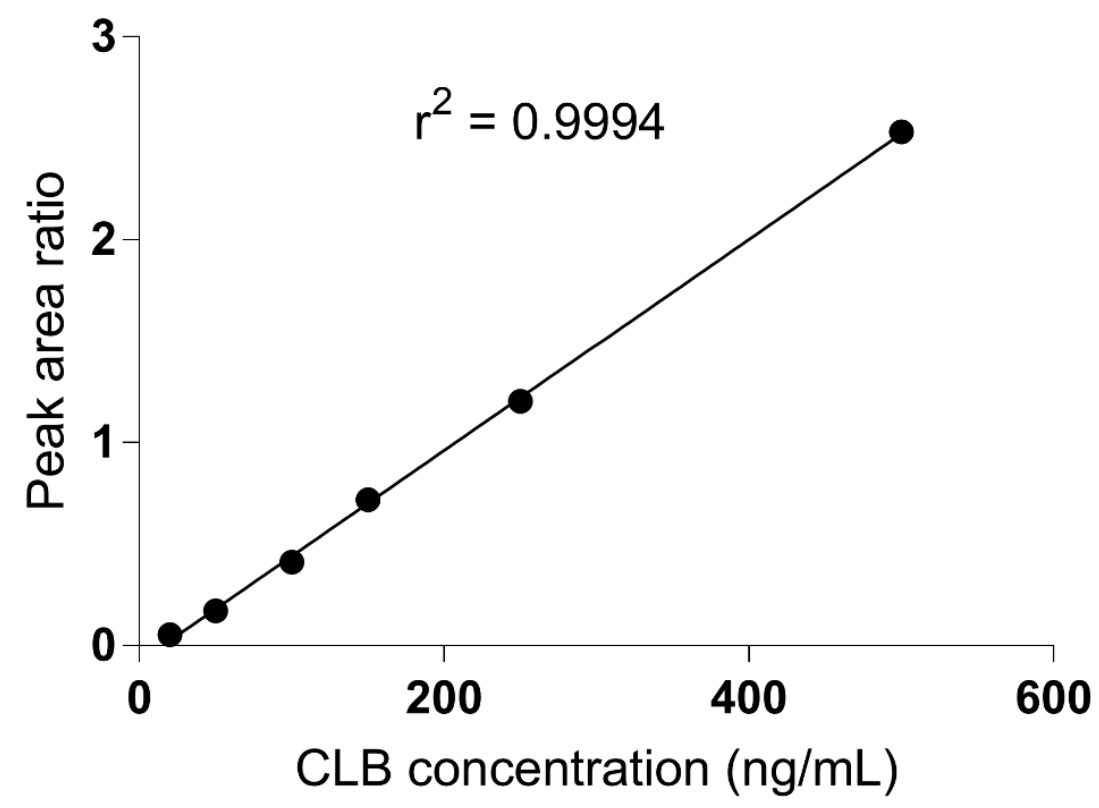

B

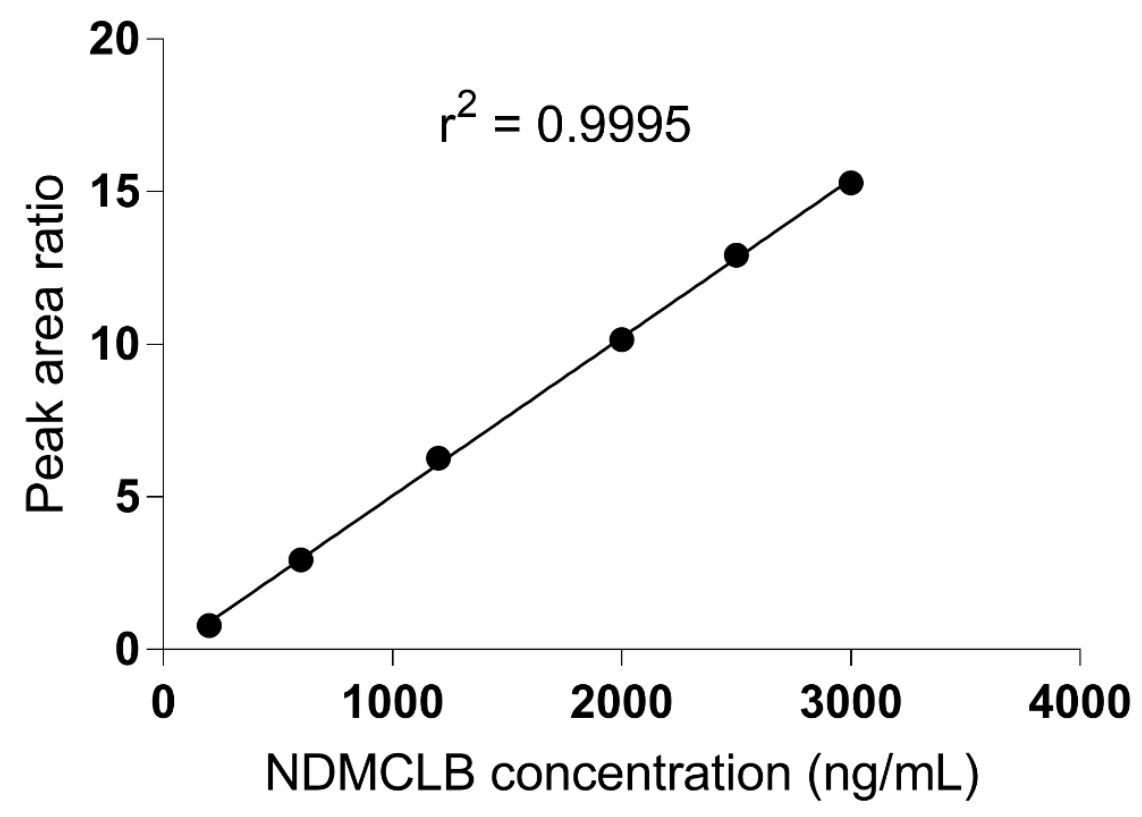

Figure 3. (A) Linearity of clobazam (CLB) over range $20-500 \mathrm{ng} / \mathrm{mL}$; (B) linearity of $\mathrm{N}$-desmethylclobazam (NDMCLB) over range $200-3000 \mathrm{ng} / \mathrm{mL}$.

\subsubsection{Precision and Accuracy}

The intra-day and inter-day precision and accuracy were acceptable for CLB. The intra-day and inter-day CVs for CLB were $<8 \%$ and $12 \%$, respectively, with the exception of the inter-day lowest concentration CV $(<16 \%)$ (Table 1). The intra-day and inter-day percent errors were within $\pm 10 \%$. The metabolite NDMCLB also had an acceptable CV $(<6 \%)$ and percent error (within $\pm 6 \%$ ) for both inter- and intra-day (Table 2 ). 
Table 1. Inter- and intra-day accuracy (\%error) and precision (\%CV) for clobazam (CLB).

\begin{tabular}{ccccc}
\hline & Concentration $(\mathbf{n g} / \mathbf{m L})$ & Observed Concentration $(\mathbf{n g} / \mathbf{m L})$-Mean \pm SD & CV (\%) & Percent Error \\
\hline Inter-day $(n=19)$ & 20 & $19.2 \pm 3.0$ & 15.4 & 11.4 \\
& 60 & $55.9 \pm 6.4$ & 5.4 & -4.5 \\
& 150 & $151.5 \pm 8.3$ & 8.4 & -6.8 \\
& 400 & $388.5 \pm 32.6$ & 6.1 & -2.9 \\
\hline Intra-day $(n=5)$ & 20 & $18.6 \pm 1.1$ & 7.8 & -6.9 \\
& 60 & $65.5 \pm 5.1$ & 3.7 & 9.2 \\
& 150 & $159.6 \pm 5.8$ & 2.4 & 0.3 \\
\hline
\end{tabular}

$\mathrm{CV}$, coefficient of variation.

Table 2. Inter- and intra-day accuracy (\%error) and precision $(\% \mathrm{CV})$ for $\mathrm{N}$-desmethylclobazam (NDMCLB).

\begin{tabular}{|c|c|c|c|c|}
\hline & Concentration $(\mathrm{ng} / \mathrm{mL})$ & Observed Concentration $(\mathrm{ng} / \mathrm{mL})-$ Mean \pm SD & CV (\%) & Percent Error \\
\hline \multirow[t]{4}{*}{ Inter-day $(n=15)$} & 200 & $201.3 \pm 9.5$ & 4.7 & 0.7 \\
\hline & 600 & $564.8 \pm 16.3$ & 2.9 & -5.9 \\
\hline & 1600 & $1567.0 \pm 56.7$ & 3.6 & -2.1 \\
\hline & 2500 & $2456.9 \pm 132.4$ & 5.4 & -1.7 \\
\hline \multirow[t]{4}{*}{ Intra-day $(n=5)$} & 200 & $189.7 \pm 5.7$ & 3.0 & -5.2 \\
\hline & 600 & $546.5 \pm 29.6$ & 5.4 & -8.9 \\
\hline & 1600 & $1517.6 \pm 58.4$ & 3.8 & -5.1 \\
\hline & 2500 & $2526.6 \pm 90.6$ & 3.6 & 1.1 \\
\hline
\end{tabular}

$\mathrm{CV}$, coefficient of variation.

\subsubsection{Recovery}

The average extraction recovery obtained from analyzing three QC concentrations for each drug $(60,150,400 \mathrm{ng} / \mathrm{mL}$ for CLB and 600, 1600, and $2500 \mathrm{ng} / \mathrm{mL}$ for NDMCLB) is shown in Table 3. The mean recovery percentages of CLB ranged from $95.7 \pm 5.2 \%$ to $98 \pm 3.8$ with a $C V$ of $<6 \%$ while the metabolite's average recovery ranged from $92.5 \pm 1.9 \%$ to $102.1 \pm 1.2 \%$ with $\mathrm{CV}<7 \%$.

Table 3. Mean percent recovery for clobazam (CLB) and N-desmethylclobazam (NDMCLB).

\begin{tabular}{cccc}
\hline Drug & Concentration (ng/mL) & Recovery, Mean \pm SD (\%) & CV (\%) \\
\hline CLB & 60 & $95.7 \pm 5.2(n=3)$ & 5.4 \\
& 150 & $98.0 \pm 3.8(n=3)$ & 3.8 \\
& 400 & $97.7 \pm 1.5(n=3)$ & 1.6 \\
NDMCLB & 600 & $102.1 \pm 1.2(n=3)$ & 2.1 \\
& 1600 & $92.5 \pm 1.9(n=3)$ & 6.0 \\
\hline Diazepam & 2500 & $96.6 \pm 5.8(n=3)$ & 1.7 \\
\hline$n=3$ per concentration; CV, coefficient of variation. & &
\end{tabular}

\section{Discussion}

CLB is a benzodiazepine antiepileptic drug that has been shown to be effective in many types of refractory epilepsy and has been in use since 1984 [1-3]. CLB is mainly metabolized by cytochrome P450 enzymes. Its major metabolite, NDMCLB, is an active metabolite and has a longer half-life than the parent drug (59-74 h vs. 36-42 h, respectively), significantly contributing to CLB pharmacological activity [25]. This paper describes a rapid, reliable, and simple method for measuring CLB and its metabolite NDMCLB in human plasma and the time needed for sample analysis is only $15 \mathrm{~min}$. This method only requires one isocratic pump and one channel of detection for both analytes of interest and it involves one liquidliquid extraction step with reasonable extraction recovery. Additionally, one key advantage of the described method over most of the reported methods is the relatively small volume of samples needed ( $0.3 \mathrm{~mL}$ as opposed to $1 \mathrm{~mL}$ in most methods) $[17,18,21-24]$, which makes this analytical method feasible for research purposes as well as routine monitoring of CLB and its metabolite. Compared to what has been previously reported [20], we used a single 
isocratic mixture of acetonitrile and water, adding to the simplicity of the method without affecting the efficiency of separation $[17,18,21-24]$. CLB and NDMCLB have no established reference range; however, it has been suggested that CLB and NDMCLB references ranges are 30-300 $\mathrm{ng} / \mathrm{mL}$ and 300-3000 $\mathrm{ng} / \mathrm{mL}$, respectively [7]. In another study, the reported CLB concentration in plasma was from 100 to $400 \mathrm{ng} / \mathrm{mL}$ [26]. These concentrations are within our dynamic range. Therefore, our method is practical in research purposes investigating exposure to CLB and its metabolite in human plasma.

\section{Conclusions}

In conclusion, this paper describes a rapid, reliable, and simple method for measuring CLB and its metabolite NDMCLB in human plasma. This described UV-HPLC procedure offers acceptable precision and accuracy to quantify CLB and its metabolite plasma concentrations.

Author Contributions: Conceptualization, S.H.M.; methodology, S.H.M. and F.A.I.; validation, S.H.M. and F.A.I.; formal analysis, S.H.M. and F.A.I.; writing—original draft preparation, F.A.I.; writing - review and editing, S.H.M. and F.A.I.; supervision, S.H.M.; funding acquisition, S.H.M. Both authors have read and agreed to the published version of the manuscript.

Funding: This research was funded by an investigator start-up fund for Sherif Hanafy Mahmoud from the Faculty of Pharmacy and Pharmaceutical Sciences, University of Alberta.

Data Availability Statement: All relevant data are within the manuscript.

Conflicts of Interest: The authors declare no conflict of interest.

\section{References}

1. Robertson, M.M. Current Status of the 1,4- and 1,5-Benzodiazepines in the Treatment of Epilepsy: The Place of Clobazam. Epilepsia 1986, 27 (Suppl. S1), S27-S41. [CrossRef]

2. Pernea, M.; Sutcliffe, A.G. Clobazam and Its Use in Epilepsy. Pediatr. Rep. 2016, 8, 34-38. [CrossRef]

3. Mahmoud, S.H.; Rans, C. Systematic review of clobazam use in patients with status epilepticus. Epilepsia Open 2018, 3, 323-330. [CrossRef]

4. $\quad$ Grigoleit, H.-G.; Hajdú, P.; Hundt, H.K.L.; Koeppen, D.; Malerczyk, V.; Meyer, B.H.; Müller, F.; Witte, P.U. Pharmacokinetic aspects of the interaction between clobazam and cimetidine. Eur. J. Clin. Pharmacol. 1983, 25, 139-142. [CrossRef] [PubMed]

5. Monjanel-Mouterde, S.; Antoni, M.; Bun, H.; Botta-Frindlund, D.; Gauthier, A.; Durand, A.; Cano, J.P. Pharmacokinetics of a Single Oral Dose of Clobazam in Patients with Liver Disease. Pharmacol. Toxicol. 1994, 74, 345-350. [CrossRef] [PubMed]

6. Theis, J.G.; Koren, G.; Daneman, R.; Sherwin, A.L.; Menzano, E.; Cortez, M.; Hwang, P. Interactions of clobazam with conventional antiepileptics in children. J. Child Neurol. 1997, 12, 208-213. [CrossRef] [PubMed]

7. De Leon, J.; Spina, E.; Diaz, F.J. Clobazam Therapeutic Drug Monitoring: A Comprehensive Review of the Literature with Proposals to Improve Future Studies. Ther. Drug Monit. 2013, 35, 30-47. [CrossRef] [PubMed]

8. Caccia, S.; Ballabio, M.; Guiso, G.; Zanini, M.G. Gas-liquid chromatographic determination of clobazam and n-desmethylclobazam in plasma. J. Chromatogr. 1979, 164, 100-105. [CrossRef]

9. Marliac, Y.; Barazi, S. Determination of unchanged clobazam in plasma by gas-liquid chromatography. Ann. Pharm. Françaises $1989,47,213-220$.

10. Riva, R.; Tedeschi, G.; Albani, F.; Baruzzi, A. Quantitative determination of clobazam in the plasma of epileptic patients by gas-Liquid chromatography with electron-capture detection. J. Chromatogr. B Biomed. Sci. Appl. 1981, 225, 219-224. [CrossRef]

11. Simonsen, K.W.; Hermansson, S.; Steentoft, A.; Linnet, K. A Validated Method for Simultaneous Screening and Quantification of Twenty-Three Benzodiazepines and Metabolites Plus Zopiclone and Zaleplone in Whole Blood by Liquid-Liquid Extraction and Ultra-Performance Liquid Chromatography-Tandem Mass Spectrometry. J. Anal. Toxicol. 2010, 34, 332-341. [CrossRef] [PubMed]

12. Mikayelyan, A.; Aleksanyan, A.; Sargsyan, M.; Gevorgyan, A.; Zakaryan, H.; Harutyunyan, A.; Zhamharyan, L.; Armoudjian, Y.; Margaryan, T. Protein Precipitation Method for Determination of Clobazam and N-Desmethylclobazam in Human Plasma by Lc-Ms/Ms. Biomed. Chromatogr. 2020, 34, e4710. [CrossRef] [PubMed]

13. Laloup, M.; Fernandez, M.D.M.R.; De Boeck, G.; Wood, M.; Maes, V.; Samyn, N. Validation of a Liquid Chromatography-Tandem Mass Spectrometry Method for the Simultaneous Determination of 26 Benzodiazepines and Metabolites, Zolpidem and Zopiclone, in Blood, Urine, and Hair. J. Anal. Toxicol. 2005, 29, 616-626. [CrossRef] [PubMed]

14. Knapp, J.; Boknik, P.; Gumbinger, H.G.; Linck, B.; Luss, H.; Muller, F.U.; Schmitz, W.; Vahlensieck, U.; Neumann, J. Quantitation of Clobazam in Human Plasma Using High-Performance Liquid Chromatography. J. Chromatogr. Sci. 1999, 37, 145-149. [CrossRef] [PubMed] 
15. Bolner, A.; Tagliaro, F.; Lomeo, A. Optimised determination of clobazam in human plasma with extraction and high-performance liquid chromatography analysis. J. Chromatogr. B Biomed. Sci. Appl. 2001, 750, 177-180. [CrossRef]

16. Rouini, M.; Ardakani, Y.H.; Hakemi, L.; Mokhberi, M.; Badri, G. Simultaneous determination of clobazam and its major metabolite in human plasma by a rapid HPLC method. J. Chromatogr. B 2005, 823, 167-171. [CrossRef]

17. Ratnaraj, N.; Goldberg, V.; Lascelles, P.T. Determination of clobazam and desmethylclobazam in serum using high-performance liquid chromatography. Analyst 1984, 109, 813-815. [CrossRef]

18. Pistos, C.; Stewart, J.T. Direct injection HPLC method for the determination of selected benzodiazepines in plasma using a Hisep column. J. Pharm. Biomed. Anal. 2003, 33, 1135-1142. [CrossRef]

19. Tomasini, J.-L.; Bun, H.; Coassolo, P.; Aubert, C.; Cano, J.-P. Determination of Clobazam, n-desmethylclobazam and their hydroxy metabolites in plasma and urine by high-performance liquid chromatography. J. Chromatogr. B Biomed. Sci. Appl. 1985, 343, 369-377. [CrossRef]

20. Kunicki, P. Simple and sensitive high-performance liquid chromatographic method for the determination of 1,5-benzodiazepine clobazam and its active metabolite $N$-desmethylclobazam in human serum and urine with application to 1,4-benzodiazepines analysis. J. Chromatogr. B Biomed. Sci. Appl. 2001, 750, 41-49. [CrossRef]

21. Akerman, K.K. Analysis of clobazam and its active metabolite norclobazam in plasma and serum using HPLC/DAD. Scand. J. Clin. Lab. Investig. 1996, 56, 609-614. [CrossRef]

22. Dusci, L.J.; Hackett, L.P.; Dusci, L.J.; Hackett, L.P. Simultaneous Determination of Clobazam, N-Desmethyl Clobazam and Clonazepam in Plasma by High Performance Liquid Chromatography. Ther. Drug Monit. 1987, 9, 113-116. [CrossRef]

23. Brachet-Liermain, A.; Jarry, C.; Faure, O.; Guyot, M.; Loiseau, P. Liquid Chromatography Determination of Clobazam and Its Major Metabolite N-Desmethylclobazam in Human Plasma. Ther. Drug Monit. 1982, 4, 301-306. [CrossRef] [PubMed]

24. Zilli, M.A.; Nisi, G. Simple and sensitive method for the determination of clobazam, clonazepam and nitrazepam in human serum by high-performance liquid chromatography. J. Chromatogr. B Biomed. Sci. Appl. 1986, 378, 492-497. [CrossRef]

25. Tolbert, D.; Larsen, F. A Comprehensive Overview of the Clinical Pharmacokinetics of Clobazam. J. Clin. Pharmacol. 2019, 59, 7-19. [CrossRef] [PubMed]

26. Schulz, M.; Schmoldt, A. Therapeutic and toxic blood concentrations of more than 500 drugs. Die Pharm. 1997, 52, 895-911. 